\title{
Intrauterine Diagnosis of Genodermatoses
}

\author{
Yuval Ramot
}

Published online: 3 September 2013

(C) Springer Science+Business Media New York 2013

\begin{abstract}
The progress of molecular genetics led to a revolution in prenatal diagnosis of inherited diseases, which also had affected the dermatology field profoundly. New molecular techniques have replaced fetal skin biopsies, which were previously used. Nowadays, we are standing on the brink of great changes, with the advent of noninvasive assays based on fetal cells and fetal DNA residing in the maternal blood. This review is aimed to give the dermatologist a current overview of the available methods for prenatal diagnosis, with an emphasis on genodermatoses.
\end{abstract}

Keywords Prenatal diagnosis · Pregnancy $\cdot$ Chorionic villous sampling $\cdot$ Amniocentesis $\cdot$ Genodermatoses

\section{Introduction}

In the past, prenatal diagnosis for genodermatoses was complicated and risky, involving an invasive fetal skin biopsy (FSB). However, nowadays, with the advent of gene discovery, and with almost all genes responsible for the severe genodermatoses revealed, DNA-based prenatal diagnosis became a clinical-service reality [1]. Although invasive procedures are still necessary to acquire fetal cells, new noninvasive techniques are becoming available. These assays are based on fetal cells or fetal DNA in the maternal blood [2•]. This review was designed to provide a current overview of the available methods for prenatal diagnosis, with an emphasis on genodermatoses.

Y. Ramot $(\bowtie)$

Department of Dermatology, Hadassah - Hebrew University

Medical Center, PO Box 12000, Jerusalem 9112001, Israel

e-mail: yramot@gmail.com

\section{Fetal Skin Biopsy}

In the past, FSB was the sole available method for prenatal diagnosis of genodermatoses and was mainly utilized for diagnosis of epidermolysis bullosa and ichthyoses [3]. In the beginning, a "blind" method was used to obtain fetal skin, with a very low efficiency and high rates of maternal and fetal injuries or infection [4]. Later, new techniques were developed, and FSB was performed with the aid of fetoscopy or ultrasonography [5]. This procedure was performed relatively late in pregnancy, between 15 and 22 weeks gestation [6]. The skin biopsy was analyzed with light and transmission electron microscopy, and later, with the development of specific antibodies, immunohistochemical tests were performed on the skin samples [6, 7]. Nowadays, FSB is hardly utilized, due to the introduction of newer molecular diagnostic procedures. FSB is an invasive method, prone to false-positive (due to mechanical trauma) and -negative (due to inadequate skin sampling) results [5]. Additionally, it has risk for fetal loss (1-3\%), amniotic fluid leakage, and fetal scarring [8], and the number of centers with the experience and expertise to per-

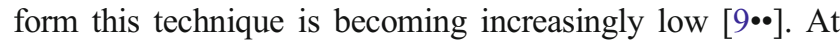
present, FSB is indicated in cases where insufficient DNA data are available, such as when the causative gene is unknown or the specific mutation could not be identified [9・•, $10 \bullet \cdot$. FSB also might be useful in de novo cases, where there is a suspicion of a genodermatosis (such as epidermolysis bullosa with pyloric atresia) [11].

\section{Amniocentesis}

Whereas amniocentesis was first introduced for genetic diagnosis in the late 1960s only for high-risk pregnancies [12], it is currently the most commonly used invasive procedure for prenatal diagnosis in the second trimester of pregnancy. This 
procedure includes insertion of a needle through the skin and uterus into the amniotic cavity and aspiration of amniotic fluid, which contains fetal cells [13]. This procedure is usually performed around the 16 week of gestation and is usually guided by an ultrasound [13]. "Early" amniocentesis between gestation weeks 9 to 14 also can be performed, but it yields less amniotic fluid [14].

Complications from this procedure include transient vaginal spotting or leakage of amniotic fluid (1-2\%) and rarely chorioamnionitis $(<0.1 \%)$. The rate of fetal loss has declined dramatically in recent years, and it is estimated that the excess fetal loss rate following this procedure is less than $0.2 \%[15,16]$.

\section{Chorionic Villus Sampling}

In contrast to amniocentesis, which aspirates amniotic fluid, chorionic villus sampling (CVS) aspirates placental tissue [17]. This procedure was first reported in China [18] and was further developed in the Western world. Aspiration is performed under ultrasound guidance either in the percutaneous transabdominal or the transvaginal/transcervical approach [17].

The major advantage of CVS on amniocentesis is the ability to perform this test early in pregnancy, and it has been performed successfully as early as 6 weeks gestation [17]. However, earlier reports suggested a higher rate of limb defects with lower gestational age [19,20], an association that was later refuted [21]. Nevertheless, most centers prefer to delay CVS until after the 10th week of gestation [17]. In addition to limb defects, CVS probably also bears a risk for fetal loss, which is comparable to second-trimester amniocentesis [22, 23•].

\section{Preimplantation Genetic Diagnosis}

The field of preimplantation genetic screening and diagnosis is maybe one of the most rapidly advancing fields in medicine. Preimplantation genetic diagnosis (PGD) was developed to avoid the need for abortions, which in addition to the psychological and physiological effects on the mother [24], often involves ethical issues [25].

Since its introduction in 1990 [26], PGD has become a wellestablished method for selecting embryos that are disease-free to be transferred to the uterus [27]. This method necessitates performing an in vitro fertilization cycle, which includes the use of exogenous hormones to stimulate ovaries to produce large number of follicles [28•, 29]. By follicular fluid aspiration, the oocytes residing inside these follicles are retrieved, and each oocyte is injected with a single spermatozoon. In order to perform PGD, three embryo biopsy techniques are available:

1. Polar body biopsy [30]: The polar body holds a complement of 23 maternal chromosomes, and therefore can be used for PGD of diseases inherited by the mother [31]. The main advantage of this method is the possibility to perform PGD even before fertilization, and thus helps to overcome legal restrictions on embryo biopsies that exist in several countries [32].

2. Cleavage stage biopsy: This is the most commonly performed embryo biopsy method, which involves the removal of one or two blastomers from the embryo in the cleavage stage. In this embryonal stage, which usually occurs by the third day, the embryo has six to eight cells. Two major limitations of this technique are possible embryo damage leading to compromise in development and misdiagnosis due to cellular mosaicism. It has been estimated that the risk for mistakenly transferring an affected fetus is $2 \%$ in autosomal recessive conditions and $11 \%$ in autosomal dominant diseases $[10 \bullet, 33]$.

3. Trophectoderm biopsy [34]: trophectoderm is the outer cell mass of the embryo, which develops by the fifth day after fertilization and develops into the placenta [32]. This technique shows better results compared with the cleavage stage biopsy and therefore is expected to become more popular for PGD [35].

A prominent technical hurdle in performing PGD is the small amount of DNA that is available for analysis in a single cell (6 pg). This obstacle can be overcome by performing nested or heminested PCR. Additionally, the high number of PCR cycles needed for single cell-PCR increases the risk for contamination, another limitation in this method [29]. Another difficulty is allele dropout, a condition in which only one of the alleles in a heterozygous sample amplifies [36], which can lead to adverse misdiagnosis. Due to these difficulties, it is recommended that CVS or amniocentesis will be performed ultimately to confirm the genetic diagnosis [28•]. Other limitations include the high cost of the procedure and limited access, in addition to lower pregnancy rates [37].

There are only a limited number of successful PGDs that have been performed for genodermatoses. PGD was performed for Herlitz junctional epidermolysis bullosa, and although pregnancy was not established in one case, an unaffected child was born in another family [38, 39]. PGD also was used for ectodermal dysplasia-skin fragility syndrome in two cases, resulting in delivery of a healthy child $[40,41]$.

\section{Noninvasive Prenatal Diagnosis}

As explained above, all invasive methods for prenatal diagnosis carry some risk for the fetus and the mother. It is for 
this reason that noninvasive methods for prenatal diagnosis have emerged.

\section{Fetal Cells in Maternal Blood}

The fact that fetal cells are present in maternal blood has been known for more than 100 years [42]. These cells can be utilized as a source for the entire fetal genome, free of any confounding maternal genetic material [43]. Therefore, these cells can be especially valuable in analysis of diseases inherited in a Mendelian fashion, because it is possible to separate the maternal allele and the fetal allele from maternal origin [44]. The main challenge in this method is the ability to isolate the fetal cells from the maternal circulation, due to their very low concentrations in the maternal blood. It has been estimated that the number of fetal cells in maternal blood is 1 in $10^{5}$ to 1 in $10^{9}$ of mononuclear cells [45]. Additionally, the final purity of the fetal cells is low, and oftentimes they are contaminated with maternal cells [45]. Other obstacles include high levels of allele dropout and cellular apoptosis upon entrance to the maternal circulation [43]. However, maybe the greatest disadvantage with this method is the fact that fetal cells can exist in maternal circulation for years, and fetal cells were found in maternal circulation even after 27 years [46]. Therefore, new techniques involving cell-free fetal genetic material have been developed.

\section{Cell-Free Fetal DNA and mRNA in Maternal Blood}

The presence of fetal DNA in maternal blood was first discovered in 1997 by Lo et al. [47], and fetal mRNA in maternal blood was described 3 years later [48]. The source of the fetal DNA is thought to be trophoblast cells that form the placenta, which undergo apoptosis and release nucleic acids [49-51]. Fetal DNA has been found to exist in concentrations of 3-6\% [52•]. The main advantage of fetal DNA compared with fetalcell based analysis is the fact that fetal DNA is cleared quickly after delivery, with a mean half-life of 16 minutes [53]. Another advantage is the fact that fetal DNA can be discovered in maternal blood as early as the fourth week of gestation, and reliably after the seventh week of gestation [54]. In addition to fetal DNA, fetal mRNA and microRNAs also exist in maternal plasma, and they can provide knowledge about fetal gene expression, mirroring different physiological conditions [48, 55-57].

A major challenge when using fetal DNA for diagnosis is how to discriminate between the fetal and maternal DNA. Therefore, this approach is mostly useful for diagnosis of mutations that are inherited from the father and are absent in the mother's genome. To overcome this problem, an approach called the relative mutation dosage was developed $[58,59]$. This method includes accurate quantification of the relative dosage of the mutant and wild-type alleles in plasma. Although this method has not been tested clinically

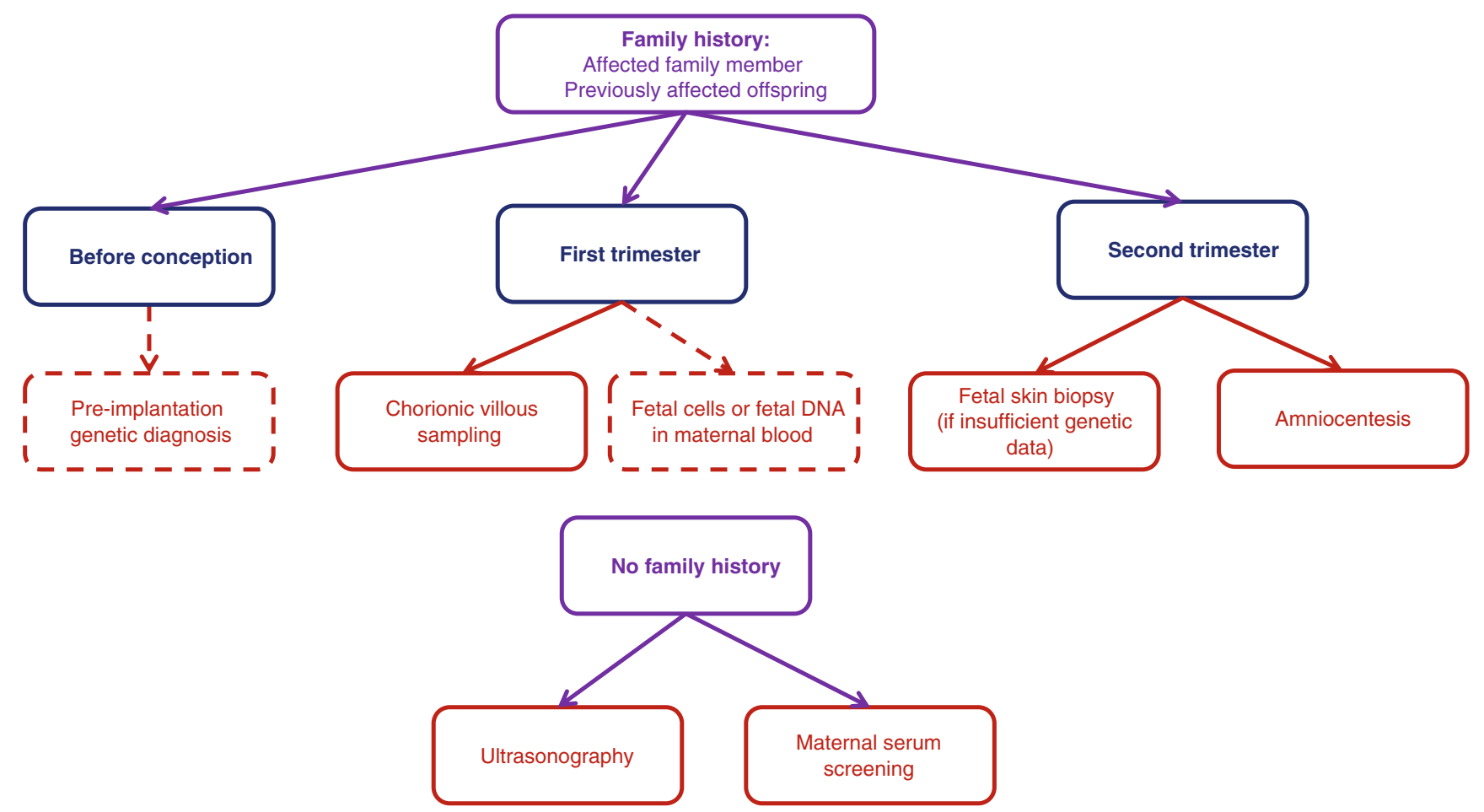

Fig. 1 A scheme summarizing the available prenatal diagnosis methods reviewed in the manuscript 
for genodermatoses, it has been utilized successfully for several inherited disorders, such as $\beta$-thalassemia and hemoglobin E disease [58], and holds promise for the future.

\section{Maternal Serum Screening}

The maternal triple-marker screen is part of the standard clinical obstetric practice and is used routinely to diagnose Down syndrome, trisomy 18 , and open neural tube defects [60]. The most common cause for extremely low levels of unconjugated estradiol, one of the markers screened in the triple test, is X-linked ichthyosis. In this condition, there is placental insufficiency of steroid sulfatase, and therefore defective steroidogenesis [61]. In case maternal serum screening reveals isolated low levels of unconjugated estradiol, amniocentesis or CVS sampling must be performed to confirm the suspicion of X-linked ichthyosis $[10 \bullet \cdot$.

\section{Ultrasonography}

Ultrasonography is a conventional method in prenatal diagnosis and is utilized commonly for this purpose. Hints for several genodermatoses can be obtained using this method, and this is especially valuable in de novo cases.

As already noted above, the presence of pyloric atresia may point at the possibility of epidermolysis bullosa, and other suggestive features may include ureteral stenosis, arthrogryposis, and nose or ear deformities [62]. Suspicion of Harlequin ichthyosis can arise based on facial dysmorphism, abnormal extremities, growth restriction, and hyperechogenic particles in the amniotic fluid [63, 64]. It has been advocated that facial dysmorphism can be displayed more clearly with the use of 3D ultrasound [65]. Other heritable skin conditions that can be detected by ultrasonography, based on their associated features, include hypohidrotic ectodermal dysplasia [66], chondroectodermal dysplasia [67], and Noonan syndrome [68]. For Noonan syndrome, it was actually shown that PTPN11 mutations are found in $11 \%$ of fetuses with isolated cystic hygroma and in $2 \%$ of fetuses with increased nuchal translucency [68].

Another example for the use of ultrasonography in diagnosing genodermatoses is tuberous sclerosis, mostly based on the finding of cardiac rhabdomyomas. The presence of cardiac rhabdomyomas is the earliest and most commonly reported finding of tuberous sclerosis [69]. Although the association of a single cardiac rhabdomyoma with tuberous sclerosis is quite vague, the presence of multiple tumors should strongly raise the suspicion for this disease $[69,70]$.

\section{Ethical Considerations}

The decision to perform a prenatal diagnosis is influenced by many factors, including religious, ethical, and intellectual values, and differ between different populations [71]. Although the question what should be considered a severe phenotype for which prenatal diagnosis should be performed is universal and true to all genetic diseases, it seems to be more problematic when relating to skin diseases [72]. Although some genodermatoses are incompatible with life and lead to significant morbidity, such as Harlequin ichthyosis and some forms of epidermolysis bullosa, many other genodermatoses can result in cosmetic problems, with no effect on life expectancy. The development of PGD further complicates the ethical intricacy $[73,74]$. It is believed that since there are no clear guidelines, each case should be carefully considered individually [72].

\section{Conclusions}

Prenatal genetic testing for severe genetic skin diseases is now common practice in many centers in the world. This field is continuously evolving, and in the future noninvasive methods are believed to be easily available. The utilization of prenatal genetic diagnosis and PGD for skin disorders that can affect quality of life, but with milder phenotypes, poses a new challenge for health care providers, raising several complicated ethical issues. A scheme summarizing the available prenatal diagnosis methods is shown in Fig. 1.

\section{Compliance with Ethics Guidelines}

Conflict of Interest Y Ramot declares no conflicts of interest.

Human and Animal Rights and Informed Consent This article does not contain any studies with human or animal subjects performed by the author.

\section{References}

Papers of particular interest, published recently, have been highlighted as:

- Of importance

•. Of major importance

1. Irvine AD. Double trouble: homozygous dominant mutations and hair loss in pachyonychia congenita. J Invest Dermatol. 2012;132:1757-9.

2. Ma Y, Gong H, Wen Y. Nucleic acid-based non-invasive prenatal diagnosis of genetic skin diseases: are we ready? Exp Dermatol. 2013;22:392-5. A recent viewpoint essay on the use of new prenatal diagnostic methods for diagnosing genodermatoses. 
3. Elias S. Use of fetoscopy for the prenatal diagnosis of hereditary skin disorders. Curr Probl Dermatol. 1987;16:1-13.

4. Esterly NB, Elias S. Antenatal diagnosis of genodermatoses. J Am Acad Dermatol. 1983;8:655-62.

5. Bakharev VA, Aivazyan AA, Karetnikova NA, Mordovtsev VN, Yantovsky YR. Fetal skin biopsy in prenatal diagnosis of some genodermatoses. Prenat Diagn. 1990;10:1-12.

6. Rodeck $\mathrm{CH}$, Nicolaides $\mathrm{KH}$. Fetoscopy and fetal tissue sampling. $\mathrm{Br}$ Med Bull. 1983;39:332-7.

7. Heagerty AH, Kennedy AR, Gunner DB, Eady RA. Rapid prenatal diagnosis and exclusion of epidermolysis bullosa using novel antibody probes. J Invest Dermatol. 1986;86:603-5.

8. Holbrook KA, Smith LT, Elias S. Prenatal diagnosis of genetic skin disease using fetal skin biopsy samples. Arch Dermatol. 1993;129:1437-54.

9. •• Fassihi H, McGrath JA. Prenatal diagnosis of epidermolysis bullosa. Dermatol Clin. 2010;28:231-7. viii. A review on the techniques available today for prenatal diagnosis of epidermolysis bullosa.

10. •- Luu M, Cantatore-Francis JL, Glick SA. Prenatal diagnosis of genodermatoses: current scope and future capabilities. Int J Dermatol. 2010;49:353-61. This article reviews the available methods for prenatal diagnosis, with emphasis on skin disorders.

11. Maurice P, Eyrolle-Guignot D, Dhombres F, Garel C, Gonzales M, Muller F, et al. The key role of ultrasound examination in the prenatal diagnosis of epidermolysis bullosa with pyloric atresia. Prenat Diagn. 2013;1-2. doi:10.1002/pd.4137.

12. Jacobson CB, Barter RH. Intrauterine diagnosis and management of genetic defects. Am J Obstet Gynecol. 1967;99:796-807.

13. Mujezinovic F, Alfirevic Z. Technique modifications for reducing the risks from amniocentesis or chorionic villus sampling. Cochrane Database Syst Rev. 2012;8, CD008678.

14. Sundberg K, Jorgensen FS, Tabor A, Bang J. Experience with early amniocentesis. J Perinat Med. 1995;23:149-58.

15. ACOG Practice Bulletin No. 88. Invasive prenatal testing for aneuploidy. Obstet Gynecol. 2007;110:1459-67.

16. Mazza V, Pati M, Bertucci E, Re C, Ranzi A, Percesepe A, et al. Agespecific risk of fetal loss post second trimester amniocentesis: analysis of 5043 cases. Prenat Diagn. 2007;27:180-3.

17. Mujezinovic F, Alfirevic Z. Procedure-related complications of amniocentesis and chorionic villous sampling: a systematic review. Obstet Gynecol. 2007;110:687-94.

18. Department of Obstetrics and Gynaecology A. Fetal sex prediction by sex chromatin of chorionic villi cells during early pregnancy. Chin Med J. 1975;1:117-26.

19. Brambati B, Simoni G, Travi M, Danesino C, Tului L, Privitera O, et al. Genetic diagnosis by chorionic villus sampling before 8 gestational weeks: efficiency, reliability, and risks on 317 completed pregnancies. Prenat Diagn. 1992;12:789-99.

20. Firth HV, Boyd PA, Chamberlain PF, MacKenzie IZ, MorrissKay GM, Huson SM. Analysis of limb reduction defects in babies exposed to chorionic villus sampling. Lancet. 1994; 343:1069-71.

21. Froster UG, Jackson L. Limb defects and chorionic villus sampling: results from an international registry, 1992-94. Lancet. 1996;347:489-94.

22. Alfirevic Z, Sundberg K, Brigham S. Amniocentesis and chorionic villus sampling for prenatal diagnosis. Cochrane Database Syst Rev. 2003;(3):CD003252.

23. Collins SL, Impey L. Prenatal diagnosis: types and techniques. Early Hum Dev. 2012;88:3-8. A comprehensive review on available techniques for performing prenatal diagnosis.

24. Thorp Jr JM, Hartmann KE, Shadigian E. Long-term physical and psychological health consequences of induced abortion: review of the evidence. Obstet Gynecol Surv. 2003;58:67-79.

25. Chervenak FA, McCullough LB. Ethical dimensions of fetal neurology. Semin Fetal Neonatal Med. 2012;17:252-5.
26. Handyside AH, Kontogianni EH, Hardy K, Winston RM. Pregnancies from biopsied human preimplantation embryos sexed by Y-specific DNA amplification. Nature. 1990;344:768-70.

27. Spits C, Sermon K. PGD for monogenic disorders: aspects of molecular biology. Prenat Diagn. 2009;29:50-6.

28. - Brezina PR, Brezina DS, Kearns WG. Preimplantation genetic testing. BMJ. 2012;345:e5908. A clear and straightforward review on preimplantation genetic testing.

29. Vendrell X, Bautista-Llacer R. A methodological overview on molecular preimplantation genetic diagnosis and screening: a genomic future? Syst Biol Reprod Med. 2012;58:289-300.

30. Geraedts J, Montag M, Magli MC, Repping S, Handyside A, Staessen C, et al. Polar body array CGH for prediction of the status of the corresponding oocyte. Part I: clinical results. Hum Reprod. 2011;26:3173-80.

31. Verlinsky Y, Rechitsky S, Verlinsky O, Ivachnenko V, Lifchez A, Kaplan B, et al. Prepregnancy testing for single-gene disorders by polar body analysis. Genet Test. 1999;3:185-90.

32. Brezina PR, Zhao Y. The ethical, legal, and social issues impacted by modern assisted reproductive technologies. Obstet Gynecol Int. 2012;2012:686253.

33. Lewis CM, Pinel T, Whittaker JC, Handyside AH. Controlling misdiagnosis errors in preimplantation genetic diagnosis: a comprehensive model encompassing extrinsic and intrinsic sources of error. Hum Reprod. 2001;16:43-50.

34. Mamas T, Gordon A, Brown A, Harper J, Sengupta S. Detection of aneuploidy by array comparative genomic hybridization using cell lines to mimic a mosaic trophectoderm biopsy. Fertil Steril. 2012;97:943-7.

35. Harton GL, Magli MC, Lundin K, Montag M, Lemmen J, Harper JC. ESHRE PGD Consortium/Embryology Special Interest Group-best practice guidelines for polar body and embryo biopsy for preimplantation genetic diagnosis/screening (PGD/PGS). Hum Reprod. 2011;26:41-6.

36. Wilton L, Thornhill A, Traeger-Synodinos J, Sermon KD, Harper JC. The causes of misdiagnosis and adverse outcomes in PGD. Hum Reprod. 2009;24:1221-8.

37. Schaffer JV. Molecular diagnostics in genodermatoses. Semin Cutan Med Surg. 2012;31:211-20.

38. Cserhalmi-Friedman PB, Tang Y, Adler A, Krey L, Grifo JA, Christiano AM. Preimplantation genetic diagnosis in two families at risk for recurrence of Herlitz junctional epidermolysis bullosa. Exp Dermatol. 2000;9:290-7.

39. Fassihi H, Liu L, Renwick PJ, Braude PR, McGrath JA. Development and successful clinical application of preimplantation genetic haplotyping for Herlitz junctional epidermolysis bullosa. $\mathrm{Br} \mathrm{J}$ Dermatol. 2010;162:1330-6.

40. Fassihi H, Grace J, Lashwood A, Whittock NV, Braude PR, Pickering SJ, et al. Preimplantation genetic diagnosis of skin fragility-ectodermal dysplasia syndrome. Br J Dermatol. 2006;154:546-50.

41. Thornhill AR, Pickering SJ, Whittock NV, Caller J, Andritsos V, Bickerstaff HE, et al. Preimplantation genetic diagnosis of compound heterozygous mutations leading to ablation of plakophilin-1 (PKP1) and resulting in skin fragility ectodermal dysplasia syndrome: a case report. Prenat Diagn. 2000;20:1055-62.

42. Schmorl C. Pathologisch-Anatomische Untersuchungen über Puerperal Eklampsie [Pathological-anatomical explorations on puerperal eclampsia]. Leipzig: Verlag FCW Vogel; 1893.

43. Litton C, Stone J, Eddleman K, Lee MJ. Noninvasive prenatal diagnosis: past, present, and future. Mt Sinai J Med. 2009;76:521-8.

44. Hahn S, Zhong XY, Holzgreve W. Recent progress in non-invasive prenatal diagnosis. Semin Fetal Neonatal Med. 2008;13:57-62.

45. Huang Z, Fong CY, Gauthaman K, Sukumar P, Choolani M, Bongso A. Novel approaches to manipulating foetal cells in the maternal circulation for non-invasive prenatal diagnosis of the unborn child. J Cell Biochem. 2011;112:1475-85. 
46. Bianchi DW, Zickwolf GK, Weil GJ, Sylvester S, DeMaria MA. Male fetal progenitor cells persist in maternal blood for as long as 27 years postpartum. Proc Natl Acad Sci U S A. 1996;93:705-8.

47. Lo YM, Corbetta N, Chamberlain PF, Rai V, Sargent IL, Redman $\mathrm{CW}$, et al. Presence of fetal DNA in maternal plasma and serum. Lancet. 1997;350:485-7.

48. Poon LL, Leung TN, Lau TK, Lo YM. Presence of fetal RNA in maternal plasma. Clin Chem. 2000;46:1832-4.

49. Bischoff FZ, Lewis DE, Simpson JL. Cell-free fetal DNA in maternal blood: kinetics, source and structure. Hum Reprod Update. 2005;11:59-67.

50. Flori E, Doray B, Gautier E, Kohler M, Ernault P, Flori J, et al. Circulating cell-free fetal DNA in maternal serum appears to originate from cyto- and syncytio-trophoblastic cells. Case report. Hum Reprod. 2004;19:723-4.

51. Lichtenstein AV, Melkonyan HS, Tomei LD, Umansky SR. Circulating nucleic acids and apoptosis. Ann N Y Acad Sci. 2001;945:239-49.

52. - Lo YM, Chiu RW. Genomic analysis of fetal nucleic acids in maternal blood. Annu Rev Genomics Hum Genet. 2012;13:285306. This is an article reviewing the use of cell-free fetal DNA for prenatal diagnosis.

53. Lo YM, Zhang J, Leung TN, Lau TK, Chang AM, Hjelm NM. Rapid clearance of fetal DNA from maternal plasma. Am J Hum Genet. 1999;64:218-24.

54. Smith M, Visootsak J. Noninvasive screening tools for Down syndrome: a review. Int J Womens Health. 2013;5:125-31.

55. Chim SS, Shing TK, Hung EC, Leung TY, Lau TK, Chiu RW, et al. Detection and characterization of placental microRNAs in maternal plasma. Clin Chem. 2008;54:482-90.

56. Farina A, Chan CW, Chiu RW, Tsui NB, Carinci P, Concu M, et al. Circulating corticotropin-releasing hormone mRNA in maternal plasma: relationship with gestational age and severity of preeclampsia. Clin Chem. 2004;50:1851-4.

57. Ng EK, Leung TN, Tsui NB, Lau TK, Panesar NS, Chiu RW, et al. The concentration of circulating corticotropin-releasing hormone mRNA in maternal plasma is increased in preeclampsia. Clin Chem. 2003;49:727-31.

58. Lun FM, Tsui NB, Chan KC, Leung TY, Lau TK, Charoenkwan P, et al. Noninvasive prenatal diagnosis of monogenic diseases by digital size selection and relative mutation dosage on DNA in maternal plasma. Proc Natl Acad Sci U S A. 2008;105:19920-5.

59. Tsui NB, Kadir RA, Chan KC, Chi C, Mellars G, Tuddenham EG, et al. Noninvasive prenatal diagnosis of hemophilia by microfluidics digital PCR analysis of maternal plasma DNA. Blood. 2011;117:3684-91.

60. Sarikaya E, Bozdag S, Deveer R, Oguz SS, Dilmen U, Mollamahmutoglu L. Possible association of medications during pregnancy with low estriol level of the triple antenatal screening test. J Matern Fetal Neonatal Med. 2012;25:930-3.
61. Aviram-Goldring A, Goldman B, Netanelov-Shapira I, ChenShtoyerman R, Zvulunov A, Tal O, et al. Deletion patterns of the STS gene and flanking sequences in Israeli X-linked ichthyosis patients and carriers: analysis by polymerase chain reaction and fluorescence in situ hybridization techniques. Int J Dermatol. 2000;39:182-7.

62. Achiron R, Hamiel-Pinchas O, Engelberg S, Barkai G, Reichman B, Mashiach S. Aplasia cutis congenita associated with epidermolysis bullosa and pyloric atresia: the diagnostic role of prenatal ultrasonography. Prenat Diagn. 1992;12:765-71.

63. Berg C, Geipel A, Kohl M, Krokowski M, Baschat AA, Germer U, et al. Prenatal sonographic features of Harlequin ichthyosis. Arch Gynecol Obstet. 2003;268:48-51.

64. Tourette C, Tron E, Mallet S, Levy-Mozziconacci A, Bonnefont JP, D'Ercole C, et al. Three-dimensional ultrasound prenatal diagnosis of congenital ichthyosis: contribution of molecular biology. Prenat Diagn. 2012;32:498-500.

65. Vohra N, Rochelson B, Smith-Levitin M. Three-dimensional sonographic findings in congenital (harlequin) ichthyosis. J Ultrasound Med. 2003;22:737-9.

66. Sepulveda W, Sandoval R, Carstens E, Gutierrez J, Vasquez P. Hypohidrotic ectodermal dysplasia: prenatal diagnosis by three-dimensional ultrasonography. J Ultrasound Med. 2003; 22:731-5.

67. Dugoff L, Thieme G, Hobbins JC. First trimester prenatal diagnosis of chondroectodermal dysplasia (Ellis-van Creveld syndrome) with ultrasound. Ultrasound Obstet Gynecol. 2001;17:86-8.

68. Lee KA, Williams B, Roza K, Ferguson H, David K, Eddleman K, et al. PTPN11 analysis for the prenatal diagnosis of Noonan syndrome in fetuses with abnormal ultrasound findings. Clin Genet. 2009;75:190-4.

69. Jozwiak S, Kotulska K. Are all prenatally diagnosed multiple cardiac rhabdomyomas a sign of tuberous sclerosis? Prenat Diagn. 2006;26:867-9.

70. Chen CP, Su YN, Hung CC, Lee CN, Hsieh FJ, Chang TY, et al. Molecular genetic analysis of the TSC genes in two families with prenatally diagnosed rhabdomyomas. Prenat Diagn. 2005;25:176-8.

71. Pivetti M, Melotti G. Prenatal genetic testing: an investigation of determining factors affecting the decision-making process. J Genet Couns. 2013;22:76-89.

72. Fassihi H, Eady RA, Mellerio JE, Ashton GH, Dopping-Hepenstal PJ, Denyer JE, et al. Prenatal diagnosis for severe inherited skin disorders: 25 years' experience. Br J Dermatol. 2006;154:106-13.

73. Cameron $\mathrm{C}$, Williamson R. Is there an ethical difference between preimplantation genetic diagnosis and abortion? J Med Ethics. 2003;29:90-2.

74. Edwards RG. Ethics of preimplantation diagnosis: recordings from the Fourth International Symposium on Preimplantation Genetics. Reprod Biomed Online. 2003;6:170-80. 